\title{
Compensating a plastic surgeon: What is the best way to reward quality while optimizing efficiency?
}

\author{
Douglas R McKay MD MBA FRCSC ${ }^{1}$, Daniel A Peters MD MBA FRCSC ${ }^{2}$
}

\begin{abstract}
In 2011, the Canadian government spent $\$ 200$ billion on health care, $\$ 40$ billion of which went toward physician salaries (1). It is no surprise that a sum of that magnitude would attract the attention of political economists.

In early 2012, the Drummond report was released in Ontario (2). It is a government-commissioned economic road map for budgetary recovery. In simple terms, it is a cost-cutting or austerity checklist. Health care features prominently. Drummond hopes to hold health care-related spending increases at the $2.5 \%$ inflation mark for the next five years less than one-third of the historical average rise for this sector.

One suggestion of great interest is the recommendation that more than $75 \%$ of the physicians in Ontario be paid on salary in lieu of the current fee-for-service model (2). Compare this to the roughly $20 \%$ receiving alternative funding at the time of the global economic collapse (3).
\end{abstract}

\section{THIS SOUNDS GREAT, SHOW ME THE MONEY}

This seemingly simple cost-control measure quickly gives way to a wealth of underlying complexity. How do you decide how to best pay a doctor? An arbitrary allotment based on the historical average individual earnings profile for the subspecialty would be inadequate. Many Canadian doctors already receive some sort of salary. Some of these salaries supplement specific aspects of their practices, such as academia, and some are comprehensive. From the outside, these salaries sound fantastic but a complex system of metrics usually accompanies these models. There have been multitudes of alternative funding plans trialed in academic centres, family health teams and according to geographical responsibility. This myriad of models exists because no one solution is adequate.

\section{SO HOW MUCH DO I GET?}

On one of its most basic levels, the study of economics attempts to fairly assign a monetary value to goods and services. The discipline of human resource management has studied and trialed remuneration schemes since its inception, attempting to appropriately reward work performed by employees. Reward is given in exchange for advancing the interests of the organization. The goals of the organization grow from its mission statement and objectives, and are reassessed and advanced yearly or even quarterly. Specific roles or positions with the company are listed on an organization chart. The 'Org chart' defines the objectives of the employees working within the organization. Employees are grouped into bands based on salary. Salaries reflect the perceived importance of the employee's role in advancing the organization. Each employee has specific goals to meet to avoid losing their job. Incentives drive performance. When goals are surpassed, the employee moves up a band on the Org chart.

Suffice it to say that a remuneration scheme for physicians is beyond challenging. Physicians must answer to patients as well as to the needs of the organization. Imagine creating an Org chart for all physicians working in the Canadian health care system in which each role was defined task by task? Current variations in remuneration based on subspecialty are, at times, historical and not always fair. Creating bands on the health care Org chart based on specialty would reward or punish specialties, such as psychiatry and pediatrics, that classically fall on the low end of the pay scale. But how does one create a salary-based system that ignores historical inaccuracies and adequately rewards physicians for the calibre and complexity of their work?

\section{WHAT MODELS EXIST?}

Currently, there are several salary-based schemes of remuneration in play in the Canadian health care system. Those documented by the Canadian Institute for Health Information include the following: alternative remuneration for emergencies and on call hours; block funding or negotiated allocations to physicians usually in academic centres; sessional or time-based funding; salary and capitation or monthly rostered allocations typically for family physicians (3).

On the whole, physicians are a motivated group driven to do good for their patients; however, some require more motivation than others. Without some form of an accountability framework, each system is prone to pitfalls. Volume-based salaries typically rely on shadow billing to reflect productivity and justify compensation, but we know that provincial billing codes are historical. Some doctors are more efficient than others and see more patients when on a time-based salary, while others argue that efficiency sacrifices quality. Capitation can allow doctors to address complex problems but, again, volumes treated may suffer.

\section{WHAT MODEL IS BEST FOR PLASTIC SURGEONS?}

The perfect pay scheme must account for volume, complexity, efficiency and quality of care. And payments must motivate physicians to meter out preventive and cost-effective care to mitigate systemic economic collapse. When we build a more complex and comprehensive payment system, we begin to see increases in physician productivity (4). The problem is that many of these criteria fall beyond the reach of measurable metrics, and without a way to measure and gauge contribution, the perfect system remains elusive. It is far easier for governments to measure the cost of care delivery of the volume of patients treated than it is to measure the quality of outcomes.

\section{WHERE DO WE BEGIN?}

Regardless of the system used, an effective system would begin with role definition. As plastic surgeons, we must begin to discuss how we intend to define ourselves, how we would divide up our Org chart into bands, and the goals we believe we should achieve as a group to ensure our expertise and training continues to benefit our patients. The complexity of it is almost unfathomable given the breadth of the discipline, but we as a group come from a position of insight. As the individuals who operate and treat, only we can determine how to reward the complexity of what we do, and we must make these decisions within the reality of the limits imposed by our publicly funded delivery model.

\section{REFERENCES}

1. Canadian Institute for Health care Information. <www.cihi.ca> (Accessed November 3, 2011).

2. Drummond, D. Commission on the reform of Ontario's Public Services: Public Services for Ontarians, a Path to Sustainability and Excellence. Chapter 5: Health. <www.fin.gov.on.ca/en/ reformcommission/chapters/report.pdf $>$ (Accessed February, 2012).

3. Kondro W. Alternative remuneration. CMAJ 2007;176:1573.

4. Kantarevic J, Kralji B, Weinkauf D. Enhanced fee for service model and physician productivity: Evidence from Family Health Groups in Ontario. J Health Econ 2011;30:99-111.

${ }^{1}$ Division of Plastic Surgery, Department of Surgery, Queen's University, Hotel Dieu Hospital, Kingston; ${ }^{2}$ Division of Plastic Surgery, Department of Surgery and Telfer School of Management, University of Ottawa, Ottawa, Ontario

Correspondence: Dr Douglas R McKay, Division of Plastic Surgery, Department of Surgery, Queen's University, Hotel Dieu Hospital, 166 Brock Street, Brock 3R, B3031, Kingston, Ontario K7L 5G2. Telephone 613-544-3400 ext 2494, fax 613-544-3709, e-mail doug.mckay@utoronto.ca 